\title{
A Comparative Investigation on the Corrosion Behavior of cast and rolled ZG21 Mg Alloys
}

Peng Chen, Yingwei Song ", Jinhui Liu, Dayong Shan, En-Hou Han

Key Laboratory of Nuclear Materials and Safety Assessment, Institute of Metal Research, Chinese Academy of Sciences, Shenyang 110016, China

*E-mail: ywsong@imr.ac.cn

doi: $10.20964 / 2017.05 .69$

Received: 11 January 2017 / Accepted: 24 March 2017 / Published: 12 April 2017

ZG21 Mg alloys exhibit excellent deformation ability at room temperature. However, their corrosion behavior lacks sufficient investigation. The relationship between the second phases and micro-galvanic corrosion of ZG21 Mg alloys has been investigated using Atomic Force Microscopy (AFM), Scanning Kelvin Probe Force Microscopy (SKPFM), and electrochemical measurements. $\mathrm{Mg}_{3} \mathrm{Zn}_{3} \mathrm{Gd}_{2}$ second phases act as micro-cathodes due to their nobler potential than $\alpha-\mathrm{Mg}$ matrix. Localized corrosion occurs at cast ZG21, whereas general corrosion occurs at rolled ZG21. The rolled alloy shows better corrosion resistance owing to the relatively more homogeneous distribution and finer second phases.

Keywords: Second phases; ZG21 Mg alloys; AFM; SKPFM; Micro-cathodes

\section{FULL TEXT}

(C) 2017 The Authors. Published by ESG (www.electrochemsci.org). This article is an open access article distributed under the terms and conditions of the Creative Commons Attribution license (http://creativecommons.org/licenses/by/4.0/). 